\title{
ASSOCIATION OF SHELL BANDING AND HABITAT IN A COLONY OF THE LAND SNAIL THEBA PISANA
}

\author{
MICHAEL S. JOHNSON \\ Department of Zoology, University of Western Australia, \\ Nedlands, Western Australia 6009
}

Received 13.xii.79

\section{SUMMARY}

\begin{abstract}
The Mediterranean snail Theba pisana is polymorphic for shell banding. In an introduced colony in Western Australia, the frequency of effectively unbanded shells is higher in exposed habitats than in adjacent thickets of Acacia bushes. This association holds for both unbanded shells and banded shells without upper bands. These results are most easily explained in terms of climatic selection.
\end{abstract}

\section{INTRODUCTION}

THE Mediterranean land snail Theba pisana (Müller) has a complex polymorphism for shell banding. In Israel, the frequency of pale shells increases in warmer and drier regions, which Nevo and Bar (1976) explain as the result of climatic selection similar to that proposed for Cepaea nemoralis and $C$. vindobonensis (Jones, 1973). On a microgeographic scale, this hypothesis predicts that in a heterogeneous environment with exposed and sheltered habitats, pale shells should be more common in the exposed areas.

$T$. pisana is widespread and abundant in coastal dunes in southern Western Australia, where it was introduced early in this century. The colonies are generally polymorphic, and occur in a variety of habitats. This paper reports a close association of banding morph frequencies with microhabitat in a colony of $T$. pisana near Perth, Western Australia.

\section{MATERIALS AND METHODS}

\section{(i) Shell variation}

T. pisana displays a wide variety of colour and banding morphs (Taylor, 1914). In Australian colonies, the shell is white, with varying numbers and intensities of brown bands. The inheritance of the complicated banding patterns is unknown. The unbanded condition, however, is due to a single dominant allele (G. Lewis, personal communication). Banded shells vary from those with dark bands over most of the shell to those with only a series of dots along the midline. Some morphs are quite distinct, and presumably represent effects of single genes; others, however, grade into one another, suggesting polygenic control. Photographs in Hickson (1972) illustrate the banding variation such as found in the present study.

Faced with the complexity of the variation, I have adopted a functional classification similar to that used for Cepaea (Cain and Sheppard, 1954), using three categories: 
(1) Unbanded shells, which form a simple genetic class.

(2) Partially banded, a heterogeneous class of banded shells in which bands are absent from the upper half of each whorl.

(3) Fully banded, in which bands are present above the midline of each whorl.

Unbanded and partially banded shells comprise an "effectively unbanded" group, in which different genotypes underly similar phenotypes. Nevo and Bar (1976) score their samples as effectively unbanded or banded. Since there is frequently a flush of pigment on newly formed shells, even in otherwise unbanded shells, the last $90^{\circ}$ of the outermost whorl was ignored while scoring the shells.

\section{(ii) Study area}

The study site is an area of coastal dunes at the southern boundary of City Beach, Western Australia $\left(31^{\circ} 58^{\prime} \mathrm{S} ; 115^{\circ} 45^{\prime} \mathrm{E}\right)$, adjacent to the Swanbourne Rifle Range. This area was chosen for study because $T$. pisana are abundant and occupy a mosaic of well defined, contrasting habitats. The two most obvious habitat types are thickets of Acacia scrub and areas of low, open vegetation. The 2 to $2.5 \mathrm{~m}$ tall Acacia bushes provide shade, but are sufficiently sparse to allow a grassy understory. $T$. pisana aestivate on the branches of the bushes, typically 0.5 to $1.5 \mathrm{~m}$ off the ground. The open habitat consists mainly of grasses and Pelargonium, which seldom exceed $0.5 \mathrm{~m}$ in height. The most extreme of the "open" areas are the foredunes, in which patches of prostrate succulent vegetation are surrounded by bare sand. Snails in the open areas are often directly exposed to the sun, and cannot aestivate far off the ground.

The Acacia and open habitats are interspersed, forming alternate zones roughly parallel to the shore. A sand track which runs eastwards (inland) from the shore and parallel to the fence of the rifle range provides a $600 \mathrm{~m}$ transect through a sequence of five transitions between open and Acacia habitats. The study area is thus divided naturally into 6 zones. Open I includes the foredunes, extending about $100 \mathrm{~m}$ eastwards. In the easternmost $25 \mathrm{~m}$ of Open $\mathrm{I}$, the dune vegetation gives way to grass and Pelargonium. The transition from Open I to Acacia I is abrupt, occurring in about $5 \mathrm{~m}$. This Acacia thicket is about $120 \mathrm{~m}$ wide, and is separated from Acacia II by Open II, a $50 \mathrm{~m}$ wide zone. Acacia II occupies both sides of a stable dune, about $175 \mathrm{~m}$ across. Open III extends $125 \mathrm{~m}$ eastwards from Acacia II, before grading into Acacia III. Acacia III is the least well defined of the zones, with smaller and more widely spaced bushes than in Acacia I or II; but it does provide a contrast to the open habitats.

Colonies of $T$. pisana are continuous along the transect, except in the foredunes, where the habitat is discontinuous. To ensure adequate sampling in the succulent vegetation, the transect was extended southwards for about $150 \mathrm{~m}$ along the foredunes. This extension was included in Open I.

To provide additional comparisons of sheltered and open habitats, two sites were chosen at which contrasting patches of vegetation are adjacent. The first was a $5 \times 2 \mathrm{~m}$ patch of Acacia bushes surrounded by grass and succulent dune vegetation. The second was a single Olearia axillaris bush ( $2 \mathrm{~m}$ high, $2 \mathrm{~m}$ wide) within Open I, surrounded by grass and Pelargonium. In each case, snails were collected in the sheltered microhabitat and up to $5 \mathrm{~m}$ away in the open area. 


\section{(iii) Sampling}

Except in the foredunes, samples were taken at $15 \mathrm{~m}$ intervals along the transect, adjacent to the track. Each sample was taken from a $5 \times 5 \mathrm{~m}$ or smaller area. The vegetation and ground were searched thoroughly to avoid visual bias in sampling. Only live adults $(>10 \mathrm{~mm}$ diameter) were collected. Where possible, 70 to 100 snails were taken from each sampling site. Movements of the snails undoubtedly make adjacent samples nonindependent to some degree. On the other hand, I have observed significant changes in morph frequencies over distances of less than $5 \mathrm{~m}$. The $15 \mathrm{~m}$ sampling interval is thus a compromise between the need for statistical independence of the samples and the recognition of the genetic responsiveness of the snails. In the southern transect (Open I), this problem is not as great, as samples were taken at approximately $50 \mathrm{~m}$ intervals through discontinuous $T$. pisana habitat.

A partial sampling of the transects was made in June 1977 , followed by a complete sampling of 42 sites in July 1978. Although there were localised changes between years, the general pattern of morph frequencies was the same in the two years, and the data have been pooled for the present analyses.

\section{Results}

All samples were polymorphic for shell banding, but the morph frequencies varied considerably along the transect (table 1 ). Considering all 42 of the transect samples, there is a clear association of higher frequencies of effectively unbanded shells with the open habitats $(P<0 \cdot 001$, MannWhitney $U$ test). More importantly, the morph frequencies follow the habitat changes closely (fig. 1). The transect includes 5 transitions between

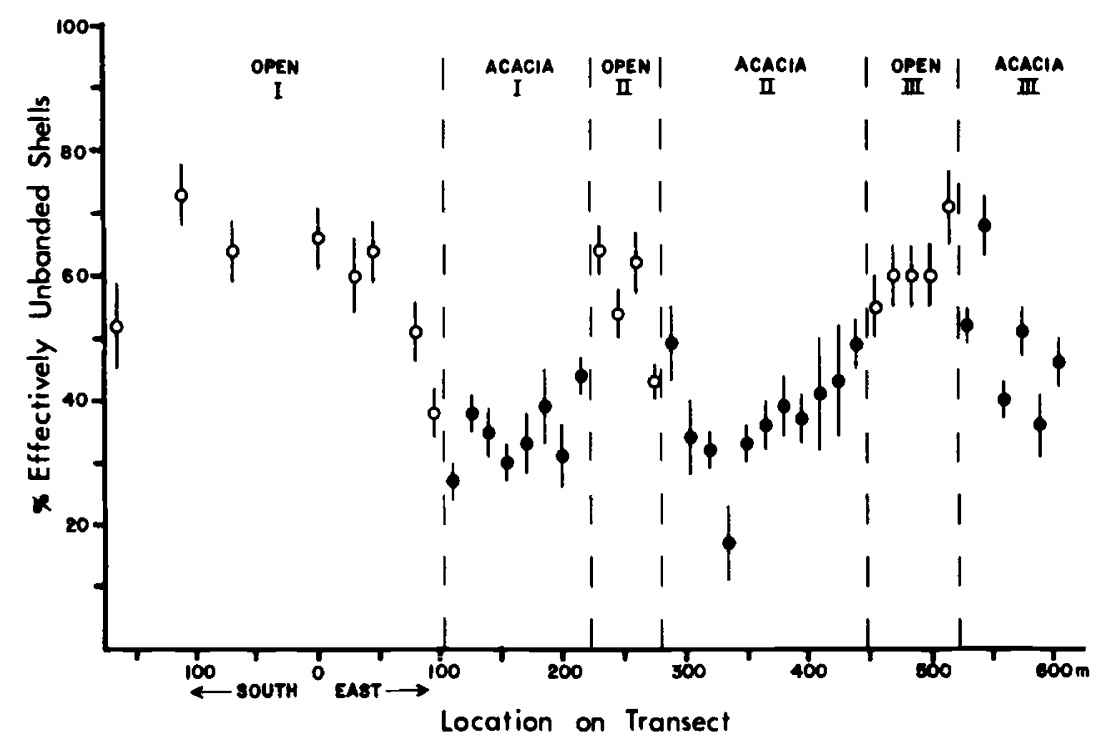

FIG. 1.-Proportions of effectively unbanded shells in samples of $T$. pisana from the City Beach transect. Open circles indicate samples from open habitats, solid circles samples from Acacia thickets. Vertical lines indicate standard errors. 
TABLE 1

Composition of samples of $\mathrm{T}$. pisana from the City Beach transect

\section{Sample}

(m)

Open I

165 south

112

68

0

30 east

45

80

95

Acacia I

110

125

140

155

170

185

200

215

Open II

230

260

275

Acacia II

290

305

320

335

350

365

380

395

410

425

440

Open III

455

470

485

500

515

Acacia III

530

545

560

575

590

605

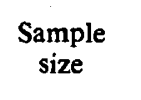

46
75
105
103
75
102
135
119

249

205

183

215

108

82
72

201

149

197

91

203

78
73

73
192

46

196

162

84

172

32

28

172

97

96

102

51

209

96

204

183

101

Unbanded $\begin{gathered}\text { Partially } \\ \text { banded }\end{gathered} \quad \begin{gathered}\text { Fully } \\ \text { banded }\end{gathered}$

Percentage effectively unbanded

Acacia and open habitats. For each comparison of sets of samples from adjacent, contrasting habitats, there is a significantly higher proportion of effectively unbanded shells in the open area than in the Acacia (MannWhitney $U$ test). The shifts in morph frequency are nearly as abrupt as the 
shifts in the vegetation, with intermediate frequencies seldom occurring more than $30 \mathrm{~m}$ on either side of a habitat boundary. Consistent with the findings from the transect, in each of the paired microhabitat comparisons, the open area had a higher proportion of effectively unbanded shells (table 2). This difference was statistically significant in both cases.

TABLE 2

Comparisons of morph frequencies in samples of $\mathrm{T}$. pisana from adjacent microhabitats

\begin{tabular}{|c|c|c|c|c|c|c|}
\hline Vegetation & \multicolumn{2}{|c|}{$\begin{array}{l}\text { Effectively } \\
\text { unbanded }\end{array}$} & \multicolumn{2}{|c|}{$\begin{array}{c}\text { Fully } \\
\text { banded }\end{array}$} & $x^{2}$ & $P$ \\
\hline $\begin{array}{l}\text { Acacia bushes } \\
\text { Succulents/grass }\end{array}$ & $\begin{array}{r}99 \\
103\end{array}$ & $\begin{array}{l}(65 \%) \\
(81 \%)\end{array}$ & $\begin{array}{l}53 \\
24\end{array}$ & $\begin{array}{l}(35 \%) \\
(19 \%)\end{array}$ & 8.83 & $<0.01$ \\
\hline $\begin{array}{l}\text { Olearia bush } \\
\text { Grass/Pelargonium }\end{array}$ & $\begin{array}{l}24 \\
54\end{array}$ & $\begin{array}{l}(25 \%) \\
(62 \%)\end{array}$ & $\begin{array}{l}71 \\
33\end{array}$ & $\begin{array}{l}(75 \%) \\
(38 \%)\end{array}$ & $25 \cdot 12$ & $<0.001$ \\
\hline
\end{tabular}

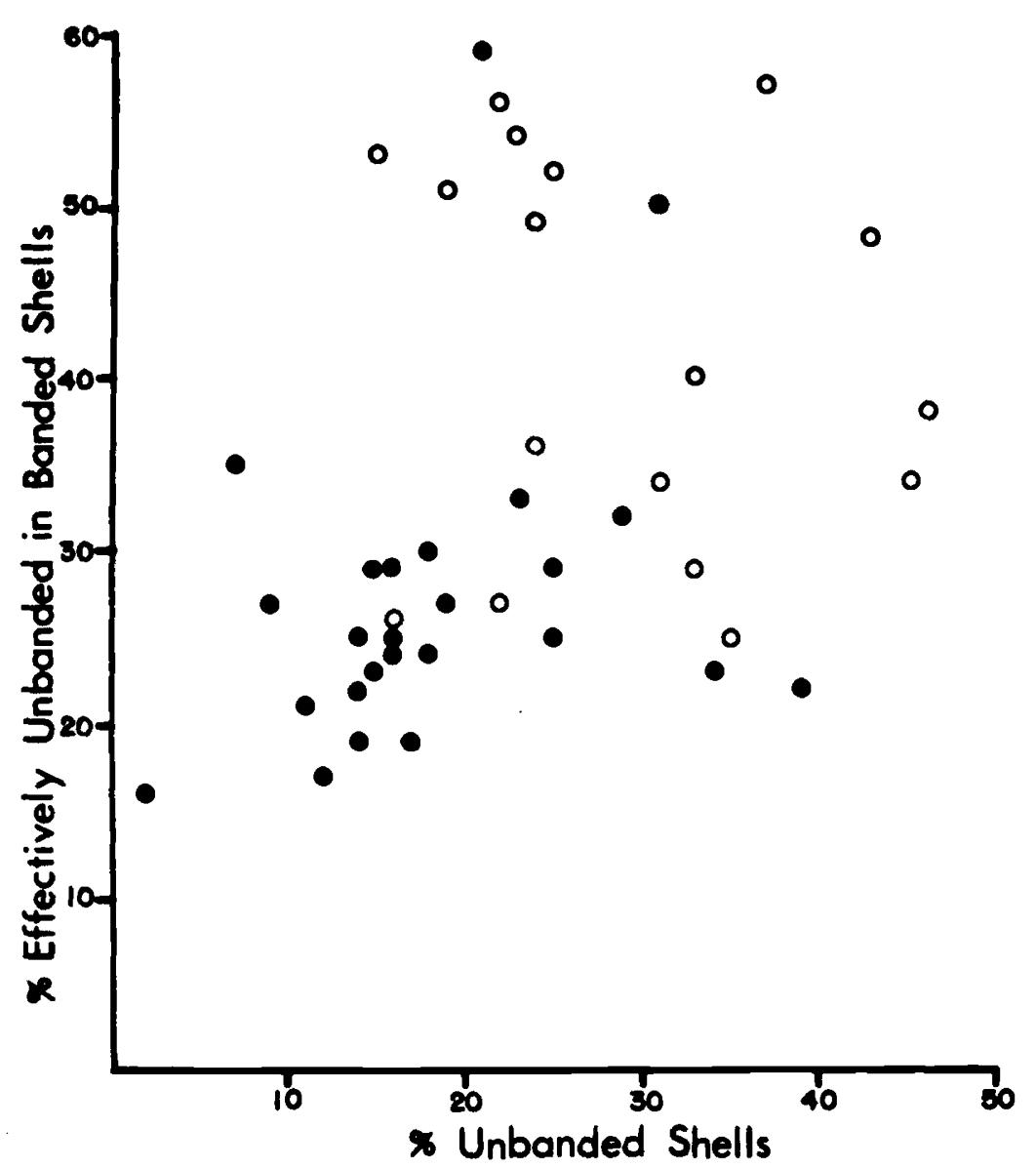

FIG. 2.-Relationship of the proportion of effectively unbanded in banded shells and the proportion of unbanded shells in samples of $T$. pisana from the transect. Open circles indicate samples from open habitats, solid circles samples from Acacia thickets. 
Effectively unbanded shells comprise two groups: genetically unbanded and genetically banded with the upper bands suppressed. Considering all of the transect samples, the frequencies of both unbanded shells and effectively unbanded in banded shells are higher in the open habitats than in the Acacia thickets (fig. 2). In the comparisons of adjacent zones, all pairs except Open III and Acacia III have significantly different frequencies for both traits (table 3). Thus, both mechanisms of producing pale shells contribute to the

TABLE 3

Comparisons of morph frequencies in Acacia and open habitats, based on Mann-Whitney $U$ tests

\begin{tabular}{lccc}
\cline { 2 - 3 } \multicolumn{1}{c}{ Sets of samples } & $\begin{array}{c}\text { Effectively } \\
\text { unbanded }\end{array}$ & $\begin{array}{c}\text { Unbanded } \\
\text { Entire transect }\end{array}$ & $\begin{array}{c}\text { Partially banded } \\
\text { in banded }\end{array}$ \\
Open I/Acacia I & ++ & +++ & +++ \\
Acacia I/Open II & ++ & +++ & ++ \\
Open II/Acacia II & ++ & + & ++ \\
Acacia II/Open III & +++ & + & ++ \\
Open III/Acacia III & + & + & +++ \\
,$+++ P<0.001 ;$ &,$++ P<0.01 ;$ &,$+ P<0.05 ;$ &,- nonsignificant.
\end{tabular}

increased paleness of colonies in the open areas. Although there is considerable scatter, the frequency of effectively unbanded in banded is correlated with the frequency of unbanded shells (fig. 2; for arcsine transformed frequencies, $r=0.40, P<0.05$ ).

\section{Discussion}

The data from $T$. pisana add to a long list of associations between habitat and morph frequencies in land snails. In reviewing these studies, Clarke et al. (1979) emphasise the need for verification of such associations in several independent comparisons, to avoid spurious correlations. The patchiness of the environment at City Beach provides a test of consistency of the response of morph frequencies to habitat changes. The transect and microhabitat samples include a total of 7 comparisons between adjacent, contrasting habitats, all of which show significantly higher frequencies of effectively unbanded shells in the open area. Even ignoring the significance of individual comparisons, the occurrence of the same trend in all 7 cases has a probability of only 0.016 by chance alone. On a larger scale, the same trend occurs on Yorke Peninsula, South Australia, where populations of $T$. pisana from inland grassy sites are monomorphic for unbanded shells, but populations from the more bushy coastal vegetation are polymorphic (Butler and Murphy, 1977).

The variation of morph frequencies over short distances in the City Beach samples is as important as the association with habitat. This orderly responsiveness contrasts with Hickson's (1972) study of sand dune colonies of $T$. pisana in South Africa, in which he attributed variation in morph frequency to random drift. His samples were taken from an area similar to Open I in the present study. Consistent with Hickson's findings, there is significant heterogeneity ( $\chi^{2}$ test) among samples within 5 of the 6 habitat 
zones of the City Beach transect (Open III is the only homogeneous group of samples). While such heterogeneity might represent drift, it more likely reflects the crudeness of the classification of habitats. In either case, the major variations in morph frequency correlate with environmental conditions, relegating drift to a minor role at most.

Although repeatable correlations of morph frequencies with environmental characteristics imply the operation of natural selection, the basis for that selection is generally elusive (Clarke, 1975). In the case of $T$. pisana, it is likely that selection is operating directly to favour pale shells in open habitats. The frequency of unbanded shells and the frequency of effectively unbanded in banded shells are genetically and statistically independent measures of the "paleness" of a population. Both of these genetic mechanisms contribute to the phenotypic responsiveness of the $T$. pisana populations, suggesting that the shell phenotype is the object of selection, as has been shown for Cepaea (e.g., Cain and Sheppard, 1954; Clarke, 1960; Richards and Murray, 1975). High frequencies of unbanded shells will reduce the effectiveness of selection on genetic modifiers of banding; likewise, high frequencies of suppressors of banding will reduce selection on the presence or absence of all bands. Consequently, the weak correlation between these two classes of effectively unbanded shells (fig. 2 ) is predictable.

The two obvious candidates for selective agents favouring pale shells in exposed habitats are microclimate and predation. Climate correlates with geographic variation of both allozymes and banding morphs of $T$. pisana in Israel, where the proportion of effectively unbanded shells increases in drier, warmer areas (Nevo and Bar, 1976). The data from City Beach confirm and extend this association on a finer scale.

Since $T$. pisana aestivate above ground through the summer, protection from overheating and dessication is crucial. The snails reduce the chances of overheating by climbing to escape high ground temperatures, and by selecting shadier sites (McQuaid et al., 1979). At City Beach, the microclimates in Acacia and open areas are different. Not only are the open areas more fully exposed to the sun, they also offer little opportunity for escape from soil heat. If, as has been shown for Cepaea vindobonensis (Jones, 1973), individuals with pale shells heat up less rapidly than those with fully banded shells, the observed association of morph frequency with habitat is explicable in terms of climatic selection. However, visual selection by predators would also be likely to favour paler shells in the more exposed areas, and any firm interpretations of the mechanisms of selection must await experimental verification.

Whatever mechanism underlies the association of morph frequency with vegetation type, the sharp clines between adjacent habitats imply strong selection and/or very limited gene flow. An additional possibility is differential habitat selection by individuals with pale or dark shells. Indeed, selection in heterogeneous environments should result in selection for attraction of each genotype towards the habitat in which it is favoured.

Acknowledgements.-I thank the many students in the Zoology Department, University of Western Australia, who helped with the collections. Of these, J. Turner provided especially great assistance and useful discussion. Dr G. Lewis provided helpful information from his studies of $T$. pisana genetics, and he and Professor J. J. Murray commented on the draft. 


\section{REFERENCES}

BUTLER, A. J., AND MURPHY, C. 1977. Distribution of introduced land snails on Yorke Peninsula, South Australia. Trans. Roy. Soc. South Australia, 101, 91-98.

CAIN, A. J., AND SHEPPARD, P. M. 1954. Natural selection in Cepaea. Genetics, 39, 89-116.

CLARKE, B. 1960. Divergent effects of natural selection on two closely related polymorphic snails. Heredity, 14, 423-443.

CLARKE, B. 1975. The contribution of ecological genetics to evolutionary theory: detecting the direct effects of natural selection on particular polymorphic loci. Genetics, 79 supplement, 101-113.

CLARKE, B., ARTHUR, W., HORSLEY, D. T., AND PARKIN, D. T. 1979. Genetic variation and natural selection in pulmonate molluscs. In Pulmonates, vol 2, ed. J. Peake. Academic Press, London.

HICKSON, T. G. L. 1972. A possible case of genetic drift in colonies of the land snail Theba pisana. Heredity, 29, 117-190.

JONES, J. S. 1973. Ecological genetics and natural selection in molluscs. Science, 182, 546-552.

MCQUAID, C. D., BRANCH, G. M., AND FROST, P. 1979. Aestivation behaviour and thermal relations of the pulmonate Theba pisana in a semi-arid environment. Thermal Biology, $4,47-55$

NEVO, E., AND BAR., Z. 1976. Natural selection of genetic polymorphisms along climatic gradients. In Population Genetics and Ecology, eds. S. Karlin and E. Nevo, pp. 159-184. Academic Press, New York.

RICHARDS, A. V., AND MURRAY, J. 1975. The relation of phenotype to habitat in an introduced colony of Cepaea nemoralis. Heredity, 34, 128-131.

TAYLOR, J. W. 1914. Monograph of the Land and Freshwater Mollusca of the British Isles. Taylor Brothers, Leeds. 